\title{
An Investigation of Abrasive Water Jet Machining on Graphite/Glass/Epoxy Composite
}

\author{
Deepak Doreswamy, ${ }^{1}$ Basavanna Shivamurthy, ${ }^{2}$ \\ Devineni Anjaiah, ${ }^{1}$ and N. Yagnesh Sharma ${ }^{1}$ \\ ${ }^{1}$ Department of Mechanical and Manufacturing Engineering, Manipal Institute of Technology, Manipal University, \\ Manipal 576104, India \\ ${ }^{2}$ School of Engineering \& IT, Department of Mechanical Engineering, Manipal University Dubai Campus, \\ Dubai International Academic City, P.O. Box 345050, Dubai, UAE
}

Correspondence should be addressed to N. Yagnesh Sharma; yagnesh.sharma@manipal.edu

Received 31 July 2014; Revised 9 November 2014; Accepted 12 December 2014

Academic Editor: SeinLeung Soo

Copyright (C) 2015 Deepak Doreswamy et al. This is an open access article distributed under the Creative Commons Attribution License, which permits unrestricted use, distribution, and reproduction in any medium, provided the original work is properly cited.

In the present research work, the effect of abrasive water jet (AWJ) machining parameters such as jet operating pressure, feed rate, standoff distance (SOD), and concentration of abrasive on kerf width produced on graphite filled glass fiber reinforced epoxy composite is investigated. Experiments were conducted based on Taguchi's $\mathrm{L}_{27}$ orthogonal arrays and the process parameters were optimized to obtain small kerf. The main as well as interaction effects of the process parameters were analyzed using the analysis of variance (ANOVA) and regression models were developed to predict kerf width. The results show that the operating pressure, the SOD, and the feed rate are found to be significantly affecting the top kerf width and their contribution to kerf width is $24.72 \%$, $12.38 \%$, and $52.16 \%$, respectively. Further, morphological study is made using scanning electron microscope (SEM) on the samples that were machined at optimized process parameters. It was observed that AWJ machined surfaces were free from delamination at optimized process parameters.

\section{Introduction}

Fiber reinforced polymer composite is used in product manufacturing due to its distinct advantages such as lower weight, higher strength and stiffness, ability to mold into complex shapes, better corrosion resistance, and damping properties. In recent days, nanofillers such as graphite particles are impregnated with glass fiber reinforced polymer (GFRP) to enhance specific properties. Shivamurthy et al. [1], found that mechanical properties of glass/epoxy composite, namely, Young's modulus, tensile strength, flexural strength, impact strength, and wear resistance, show improvement with addition of graphite flakes. Such composites are highly suitable for manufacturing of bearing liners, gears, seals, cams, wheels, brakes, rollers, clutches, bushings, and so forth. Studies on electrical properties of graphite filled composites by Goyal and Kadam [2] and Bhattacharya et al. [3] revealed that these composites are also suitable to shield electromagnetic interference in electronic devices.
Traditional machining of GFRP composites for secondary operations (trimming and drilling) is more difficult than machining of metals. A review on traditional machining of composites by Teti [4] and Abrão et al. [5] highlights the problems such as exposure of fibers to environmental attack, material degradation due to localized heating, poor dimensional accuracy, shorter tool life, delamination, and fiber pullout due to anisotropic, nonhomogeneous, and abrasive nature of such composite materials. To address these challenges, advanced machining methods have been explored. Study of machining of carbon fiber reinforced polymer (FRP) composite by electrical discharge machining [6] and laser beam machining [7] reported the formation of recast layer on cut surface due to relatively higher localized temperature. AWJ machining is a relatively new manufacturing tool which has been realized to address limitations mentioned earlier. In AWJ machining, the machined surface does not suffer from thermal damage not only due to low heat that is generated during machining but also due to water that acts as coolant. The impacting 
abrasives exert smaller cutting force on the localized spots of the work piece. Machining requires simple fixtures to support the workpiece, and hence the process does not produce mechanical distortion on the cut surface. One of the major problems encountered while machining of FRP composite by traditional methods is formation of the fine dust which leads to air pollution that causes serious lung related health problems to the machine operators. In AWJ machining, the dust generated is carried away by the water jet and also no hazardous chemical is used in the process. Hence, AWJ is considered as environmentally friendly machining process. This machine tool can be effectively used for machining of FRP composites [8]. In AWJ machining, the mixture of abrasive and water is directed on the target material. The nozzle is attached to CNC control to produce required profiles on workpiece. Material removal rate (MRR) in AWJ machining depends on operating parameters and properties of target material. In addition, other parameters such as hardness, shape, size, and quantity of abrasives laced in the water jet play a vital role in MRR [9]. Huttunen-Saarivirta et al. [10] studied the effect of particle shape on AWJ erosion process using silica sand abrasive. It was observed that spherical shaped or blunt edged abrasives tend to create ductile fracture with low MRR and angular shaped abrasive with sharp edges resulting in brittle fracture contributing to higher MRR. The effect of particle size on erosion of titanium workpiece was studied by Yerramareddy and Bahadur [11] and ElTobgy et al. [12], using experimental and finite element analysis, respectively. The erosion rate was found to increase considerably for particle size up to $200 \mu \mathrm{m}$ and remain constant for further increase in the particle size. Machining performance of various abrasives on glass workpiece was investigated by Khan and Haque [13]. Taper of the machined surface was found to increase with decrease in hardness of abrasive. Abrasive particles with higher hardness have better machining capability, but they have limitations like accelerating the wear of machine components and abrasive embedment on cut surface. Hence, AWJ machining industry uses garnet abrasive due to its specific advantages like low nozzle wear rate, good machinability, and economical availability [14-17].

In addition to abrasive properties, machining performance is also influenced by operating parameters such as jet angle, SOD, feed rate, number of cutting passes, jet pressure, abrasive flow rate, and nozzle geometry. The effect of abrasive impact angle on machining of ceramic material was investigated by Srinivasu et al. [18], using silicon carbide as abrasive. The effect of particle impact angle was also studied by Junkar et al. [19], using finite element analysis. Authors found that maximum material removal occurs at jet impact angle of $90^{\circ}$. Studies on the effect of jet pressure on cotton FRP composite by Wang and Guo [20] reported that the delamination occurs due to incapability of jet penetration into composite at lower operating pressures. Study of kerf taper angle produced on glass and graphite reinforced epoxy composite was made by Shanmugam et al. [21] and also developed a model to predict delamination length. Authors observed that, at higher operating pressures, considerable surface taper and delamination are found on the cut surface due to higher feed rates, flow turbulence, and brittle nature of composite material. Investigations on the effect of process parameters by Azmir and Ahsan [22] on glass fiber reinforced epoxy composites infer that abrasive hardness, operating pressure, SOD, and jet traverse rate were significant control factors which affect surface roughness $\left(R_{a}\right)$ and a mathematical model was developed by authors to predict $R_{a}$. Further analysis of machined surface by Azmir and Ahsan [23] shows that at a jet angle of $90^{\circ}$ glass fibers were found to be perfectly chopped. Alberdi et al. [24] studied the suitability of machinability model developed for metals to use it in composite materials. The machinability index was found to vary with thickness and composition of the composite. A comparative analysis of AWJ machining of metals in air and in submerged conditions is made by Haghbin et al. [25]. The study shows that machining under submerged conditions produced narrower kerf than the free jet machining.

In AWJ machining, the kerf profile produced depends on jet energy, jet exposure time on the workpiece, jet orientation, and material properties. Axinte et al. [26] developed a geometrical model to predict jet footprint (kerf) in maskless controlled milling applications. AWJ milling experiments were conducted on silicon carbide ceramic material at $90^{\circ}$ jet impingement angle at various jet feed rates to validate the model. Kong et al. [27] developed a mathematical model to predict the jet foot prints for arbitrarily moving jets in single straight paths. Vundavilli et al. [28] used fuzzy logic based expert system such as simulated annealing and genetic algorithm to optimize process parameters and develop a mathematical model to predict depth of cut. Zain et al. [29] also used soft computing techniques to optimize the process parameters that produced low surface roughness. Billingham et al. [30] developed model that predicts jet foot prints of the overlapped single and multiple straight paths. Narayanan et al. [31] developed model to predict the jet energy distribution by considering parameters such as abrasive particle size distribution and the effect of particle fracture. Nouraei et al. [32] developed surface evolution model that can predict the shape features in micromachining of brittle material such as borosilicate glass. These models were found to be powerful tools to develop advanced jet path strategies on complex geometries using CAD/CAM by considering various process parameters including jet exposure time and orientation. From the literature review, it is noticed that generally addition of graphite improves mechanical, tribological, and electrical properties of GFRP composite material due to which the composite finds a wide range of industrial applications. AWJ machining is the suitable method for processing of such composite materials. The literature review establishes the need to investigate the effect of operating parameters on the machinability characteristics of graphite laced GFRP. Hence, this paper attempts to explore the effect of process parameters, namely, jet operating pressure, SOD, feed rate, and abrasive concentration on kerf width, while machining of graphite filled GFRP composite and their optimization using Taguchi method. In addition, morphological study is carried out using SEM on the cut surface machined at optimum and few selected process settings. 


\section{Materials and Methods}

2.1. Materials Used. Properties of polymer composites are enhanced by impregnating the additives. In the present research, graphite of $200 \mu \mathrm{m}$ size in the particulate form was used as filler in glass fiber reinforced epoxy laminate. Bisphenol-A based epoxy resin was used as matrix; and bidirectional glass fabric of $200 \mathrm{~g} \cdot \mathrm{m}^{-2}$ was used as reinforcement to prepare the composite. Addition of graphite to the glass epoxy laminate improves wear resistance with low coefficient of friction as well as toughness. Since graphite also acts as solid lubricant, the machinability of the laminate improves. Machining is carried out by using garnet abrasive of the size 80 mesh.

2.2. Fabrication of Composite Specimen. Graphite filled GFRP laminates were prepared using hand lay-up process as shown in Figure 1. The material compositions for composite were graphite $3 \%$ by weight, glass fibers $50 \%$ by weight, and epoxy $47 \%$ by weight. Bidirectional glass fabric was cut into square shape of $250 \mathrm{~mm} \times 250 \mathrm{~mm}$. Fabric was impregnated with the graphite filled epoxy and layered one above the other. The layered green laminate was transferred to hot compression molding press and compressed with uniform pressure. Curing was done for 2 hours in compression mode at $140^{\circ} \mathrm{C}$. Postcuring was done at $180^{\circ} \mathrm{C}$ for 8 hours in free hanging condition in the furnace. The final thickness of laminate was found to be $3 \pm 0.1 \mathrm{~mm}$.

2.3. Characterization of Composite and Garnet Particles. The fabricated composite was cut into specimen size as per ASTM D638 standard. Tensile properties were estimated using a universal testing machine (Instron 3366). The hardness of the composite was measured using computerized microhardness tester (Matsuzawa-MMTX7A). The morphology of garnet abrasive and AWJ machined surfaces were analyzed using scanning electron microscope (Zeiss EVO 18, Germany). The particle size analysis of garnet abrasive was carried out as per ASTM D422 standard. The chemical composition of garnet abrasive was estimated by elemental mapping method using SEM. The kerf widths of machined surfaces were measured by tool room microscope (Mitutoyo) and the surface roughness was measured by Surtronic 3+ (Taylor Hobson).

2.4. Plan of Experiments. Design of experiment (DOE) is a powerful statistical tool to optimize the machining process parameters economically. Many researchers have used DOE to optimize the AWJ process parameters for machining various materials $[23,33]$. In the present work, experiments were designed using Taguchi's fractional factorial orthogonal array. The AWJ machining parameters and levels of the experiments were chosen based on the literature review followed by trial experiments. Table 1 shows the machining parameters that were chosen to study the performance of AWJ machining of graphite filled GFRP composite.

The main effect of operating pressure $(A)$, feed rate $(B)$, abrasive concentration $(C)$, and SOD $(D)$ as well as interaction effect of $A B, A C$, and $B C$ on the response parameter
TABLE 1: Machining parameters.

\begin{tabular}{lccc}
\hline Machining parameter/levels & 1 & 2 & 3 \\
\hline Operating pressure (MPa) & 90 & 120 & 150 \\
Feed rate (mm/min) & 75 & 100 & 125 \\
Abrasive concentration (wt.\%) & 6 & 10 & 14 \\
Standoff distance $(\mathrm{mm})$ & 1 & 3 & 5 \\
\hline
\end{tabular}

TABLE 2: Mechanical properties of the target material.

\begin{tabular}{lccc}
\hline Tensile strength & Young's modulus & \% elongation & Hardness \\
\hline $255 \mathrm{MPa}$ & $8.3 \mathrm{GPa}$ & $3.2 \%$ & VHN 30 \\
\hline
\end{tabular}

(kerf width) is considered for designing the experiment. The degree of freedom for the present experimental condition is 21 (which means the minimum number of experiments that must be conducted to estimate the effect is 21). The nearest suitable fractional orthogonal array for four factors of each three levels is $\mathrm{L}_{27}\left(4^{3}\right)$. This design is used for experiments conducted. The maximum material removal from the workpiece occurs at jet impact angle of $90^{\circ}$ [18] and the garnet is the best suitable abrasive for AWJ machining polymer composite [13]. In the present investigation, irregular and angular shaped garnet abrasive particles were uniformly dispersed with water in the mixing chamber and jet was expelled through the nozzle at $90^{\circ}$ for machining. Combinations of machining parameters used in the present study are shown in Table 4.

2.5. Experimental Setup. A three-axis CNC AWJ machine (supplied by Dardi Water Cutter Co. Ltd., make: DWJ1525FA, maximum operating pressure: $400 \mathrm{MPa}$, repeatability accuracy: $\pm 0.025 \mathrm{~mm}$ ) was used for experimentation. The experimental setup used for machining is shown in Figure 2. The garnet abrasive water jet was directed at $90^{\circ}$ on to the surface of graphite glass epoxy composite through a carbide nozzle of $0.8 \mathrm{~mm}$ focus tube diameter. A length of $20 \mathrm{~mm}$ cut was made on workpiece in each trial.

\section{Results and Discussion}

3.1. Mechanical Properties of Target Material. The tensile properties of graphite filled GFRP laminates are determined using universal testing machine (model: Instron 3366). The tensile tests are carried out on three test specimens (size as per ASTM D-638 of standard Type 5) and their average results are tabulated in Table 2. The surface hardness of the composite is determined using Vickers hardness test as per the standard loading procedure. A load of 300 grams is applied on the test specimen using $136^{\circ}$ diamond indenter for a duration of 20 seconds and the Vickers hardness number is measured using computerized microhardness tester (make: MatsuzawaMMTX7A). This test is conducted on 10 different locations on the specimen and the mean value of the Vickers hardness number is found. The mechanical properties of the workpiece are as shown in Table 2. 


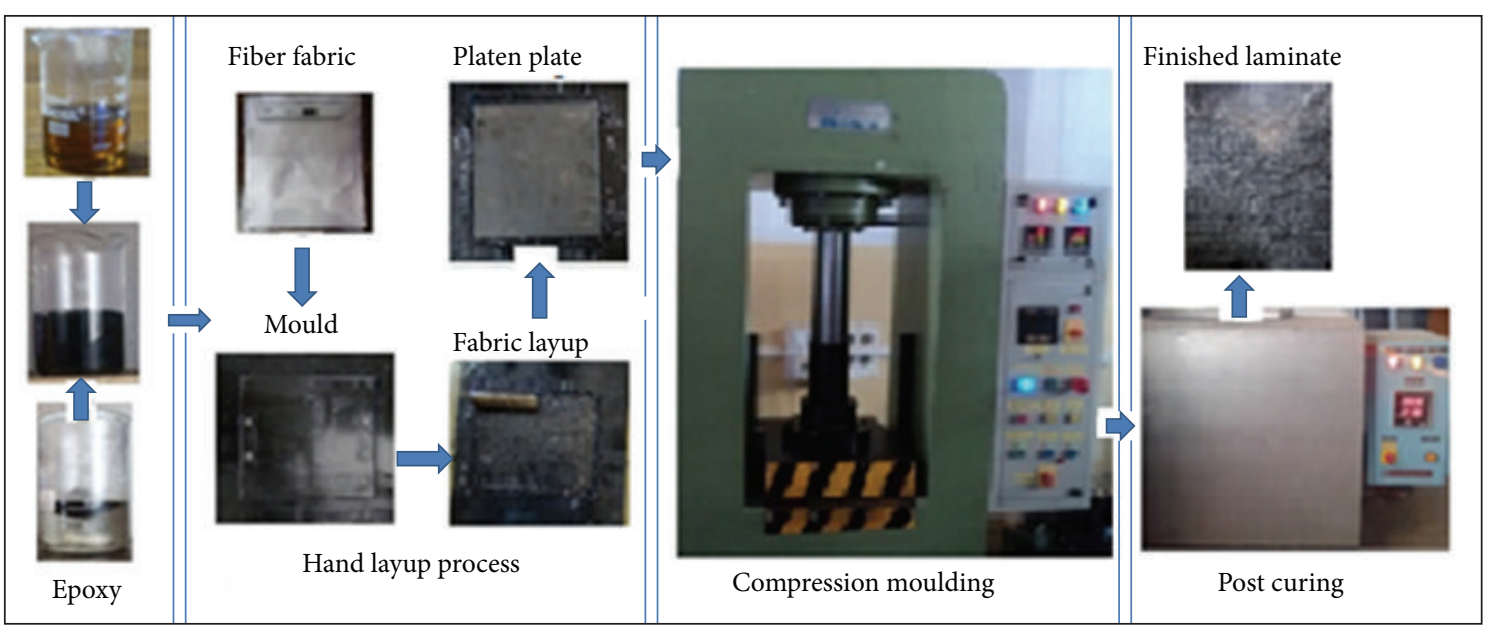

FIGURE 1: Fabrication process of graphite filled glass epoxy composite laminate.

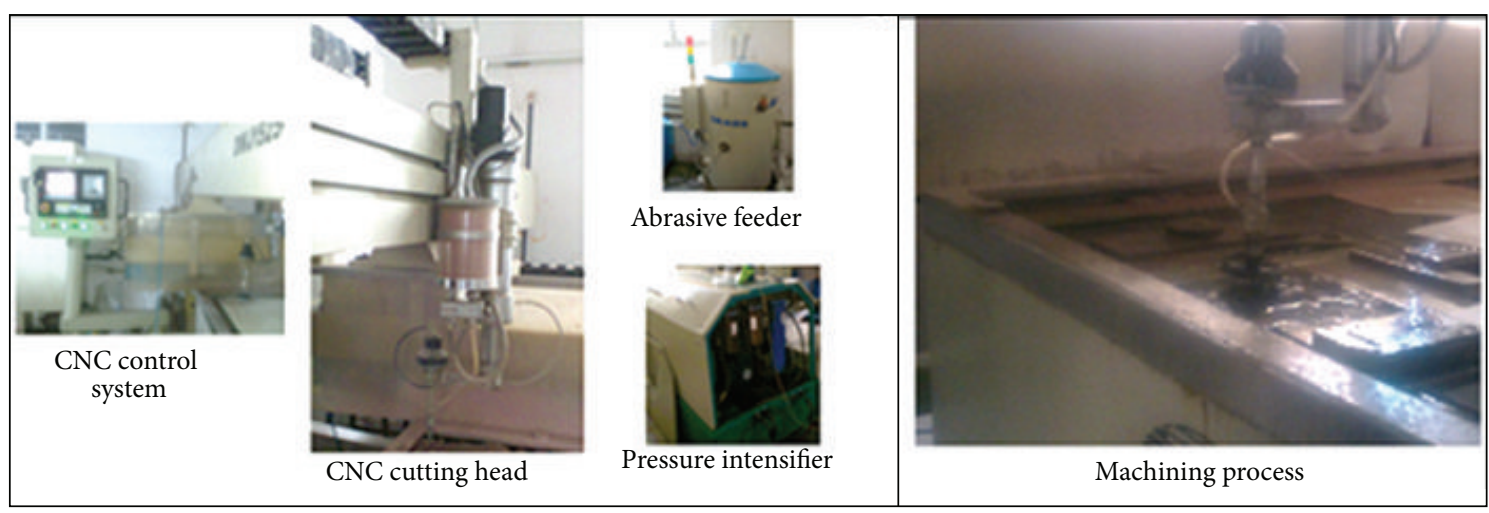

FIGURE 2: Experimental setup.

TABLE 3: Mineral composition of garnet abrasive.

\begin{tabular}{lccccccc}
\hline Element & $\mathrm{C}$ & $\mathrm{O}$ & $\mathrm{Mg}$ & $\mathrm{Al}$ & $\mathrm{Si}$ & $\mathrm{Ca}$ & $\mathrm{Fe}$ \\
\hline Quantity (wt.\%) & 6.62 & 42.84 & 1.93 & 5.82 & 9.13 & 1.23 & 32.45 \\
\hline
\end{tabular}

3.2. Characterization of Garnet Abrasive Particles. The morphology, particle size analysis, and chemical composition of the garnet abrasive were investigated using SEM (Zeiss EVO 18 special edition) before mixing into water jet. The garnet abrasives particles were coated with thin layer of conducting material (gold) by sputtering method to prevent charging of a specimen with an electron beam in SEM. Figure 3 shows the SEM image of garnet abrasive. It is observed that the abrasives have irregular sharp edges. The particle size of the garnet abrasive was investigated as per ASTM D 422. It was found that the range of particle size was $80-240 \mu \mathrm{m}$ and average particle size was around $174 \mu \mathrm{m}$. The mineral composition of garnet abrasive as per elemental mapping method by weight percent is shown in Table 3.

3.3. Effect of AWJ Process Parameters on Kerf Width. In the present work, the effect of AWJ process parameters, namely, jet pressure, feed rate, abrasive concentration, and SOD, on

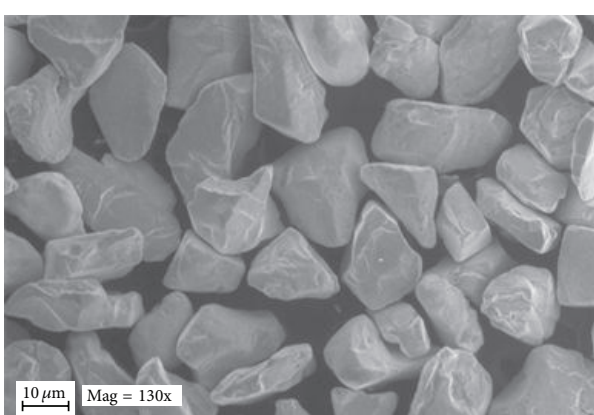

FIGURE 3: SEM image of garnet abrasive.

the top and bottom kerf width is investigated using $\mathrm{L}_{27}$ orthogonal array. The number of experiments conducted was 27 with two replications. Levels of process parameters in each run were set as mentioned in Table 4 . In each run, a cut of $20 \mathrm{~mm}$ length was made on the test sample using a 3-axis CNC AWJ machine. The width of cut at upper and lower surface is called top kerf width (TKW) and bottom kerf width (BKW), respectively. Kerf widths (responses) were measured by using tool room microscope with an accuracy of 
TABLE 4: Plan of experiment and measured output parameters.

\begin{tabular}{|c|c|c|c|c|c|c|}
\hline \multirow{2}{*}{ Trial } & \multicolumn{4}{|c|}{ Process parameters } & \multicolumn{2}{|c|}{ Average response values } \\
\hline & Pressure $(\mathrm{MPa})(1)$ & Feed rate $(\mathrm{mm} / \mathrm{min})(2)$ & Abrasive concentration (wt.\%) (5) & $\mathrm{SOD}(\mathrm{mm})(9)$ & TKW (mm) & $\mathrm{BKW}(\mathrm{mm})$ \\
\hline 1 & 90 & 75 & 6 & 1 & 0.845 & 0.803 \\
\hline 2 & 90 & 75 & 10 & 3 & 0.905 & 0.892 \\
\hline 3 & 90 & 75 & 14 & 5 & 0.964 & 0.936 \\
\hline 4 & 90 & 100 & 6 & 3 & 0.896 & 0.853 \\
\hline 5 & 90 & 100 & 10 & 5 & 0.950 & 0.912 \\
\hline 6 & 90 & 100 & 14 & 1 & 0.847 & 0.827 \\
\hline 7 & 90 & 125 & 6 & 5 & 0.870 & 0.835 \\
\hline 8 & 90 & 125 & 10 & 1 & 0.823 & 0.816 \\
\hline 9 & 90 & 125 & 14 & 3 & 0.860 & 0.850 \\
\hline 10 & 120 & 75 & 6 & 3 & 0.960 & 0.913 \\
\hline 11 & 120 & 75 & 10 & 5 & 1.176 & 1.150 \\
\hline 12 & 120 & 75 & 14 & 1 & 0.890 & 0.868 \\
\hline 13 & 120 & 100 & 6 & 5 & 1.104 & 1.055 \\
\hline 14 & 120 & 100 & 10 & 1 & 0.875 & 0.845 \\
\hline 15 & 120 & 100 & 14 & 3 & 0.981 & 0.977 \\
\hline 16 & 120 & 125 & 6 & 1 & 0.855 & 0.803 \\
\hline 17 & 120 & 125 & 10 & 3 & 0.917 & 0.852 \\
\hline 18 & 120 & 125 & 14 & 5 & 0.987 & 0.935 \\
\hline 19 & 150 & 75 & 6 & 5 & 1.203 & 1.155 \\
\hline 20 & 150 & 75 & 10 & 1 & 0.938 & 0.918 \\
\hline 21 & 150 & 75 & 14 & 3 & 1.052 & 1.005 \\
\hline 22 & 150 & 100 & 6 & 1 & 0.903 & 0.872 \\
\hline 23 & 150 & 100 & 10 & 3 & 0.965 & 0.887 \\
\hline 24 & 150 & 100 & 14 & 5 & 1.150 & 1.015 \\
\hline 25 & 150 & 125 & 6 & 3 & 0.892 & 0.880 \\
\hline 26 & 150 & 125 & 10 & 5 & 1.065 & 0.992 \\
\hline 27 & 150 & 125 & 14 & 1 & 0.882 & 0.871 \\
\hline
\end{tabular}

$0.005 \mathrm{~mm}$. In each sample, the kerf widths were measured at 5 equidistant points along the length of the cut and average values were tabulated in Table 4.

3.3.1. Effect of Jet Pressure on Kerf Width. Figure 4(a) shows the effect of pressure on top and bottom kerf widths. The percentage contribution of jet pressure on TKW is $24.72 \%$ and on BKW is $19.68 \%$. Both top and bottom kerf widths increase significantly with increase in operating pressure. This is due to the influence of increased kinetic energy and flow turbulence of the water jet at a higher pressure. The flow turbulence promotes interabrasive particle collision and jet expansion leading to increased kerf widths. Further, as the jet proceeds through the graphite filled glass epoxy composite, it loses part of its kinetic energy. Also, the abrasive particles impacting on the surface lose their sharpness and a few abrasive particles penetrate into the surface while a few other particles retard towards the top surface. Because of these reasons, the bottom kerf width is smaller than the top kerf width.
3.3.2. Effect of Feed Rate on Kerf Width. Figure 4(b) shows a significant effect of jet feed rate on kerf widths. At lower feed rate, a larger number of abrasive particles participate in the cutting action and hence produce wider kerfs. As the feed rate is increased, it is found that a reduced number of abrasive particles participate in cutting action and also tend to reduce the possibility of interaction of rebounding of particles with machined surface. Because of these reasons, the kerf widths reduce with increase in feed rate. The percentage contribution of feed rate on top and bottom kerf width is $12.38 \%$ and $15.31 \%$, respectively.

3.3.3. Effect of Concentration of Abrasive on Kerf Width. Marginal increase in kerf width is observed with increased concentration of abrasives as shown in Figure 4(c). Increase in abrasive concentration in the water increases the mass density and marginally reduces the jet velocity. At higher concentration, the dense packing of abrasives in the jet increases the possibility of interparticular collision that results in jet expansion by disintegration of the flow. This 


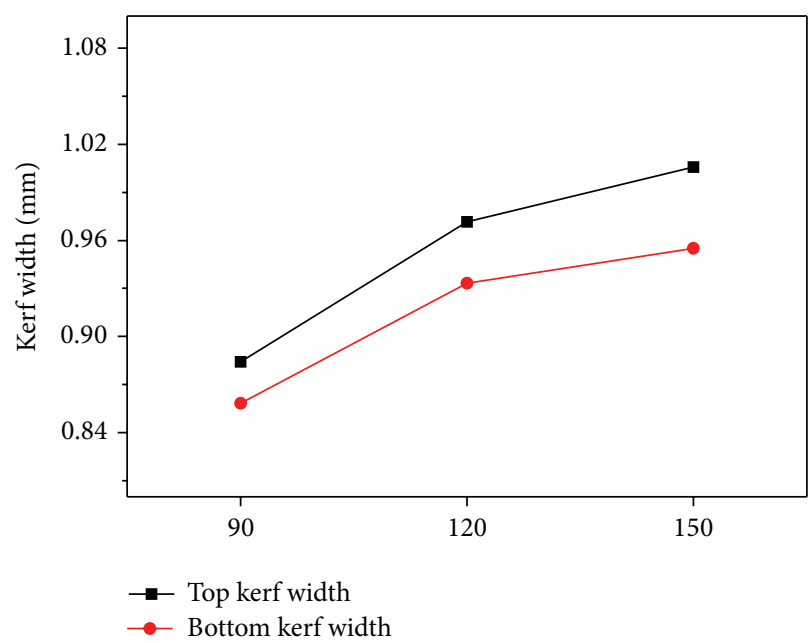

(a) Operating pressure $(\mathrm{MPa})$

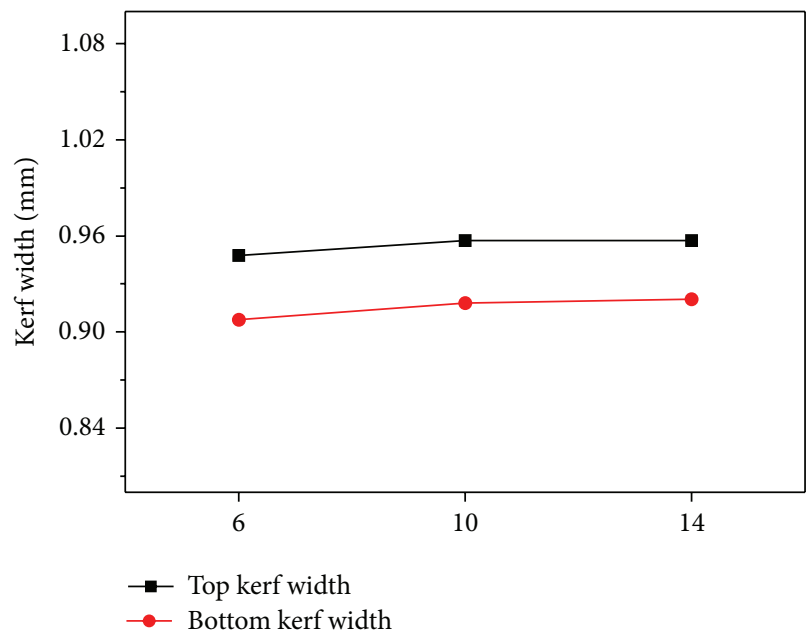

(c) Abrasive concentration (\%)

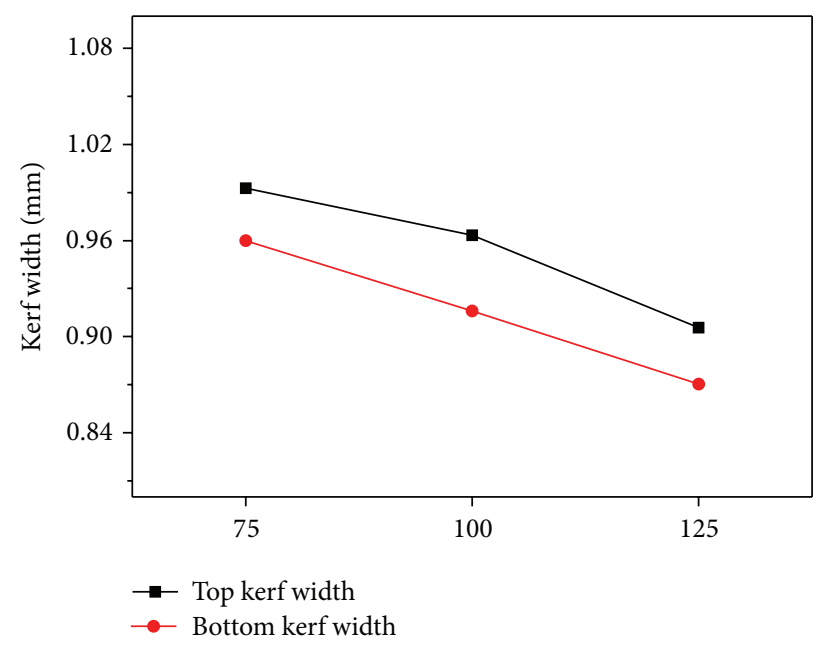

(b) Feed rate $(\mathrm{mm} / \mathrm{min})$

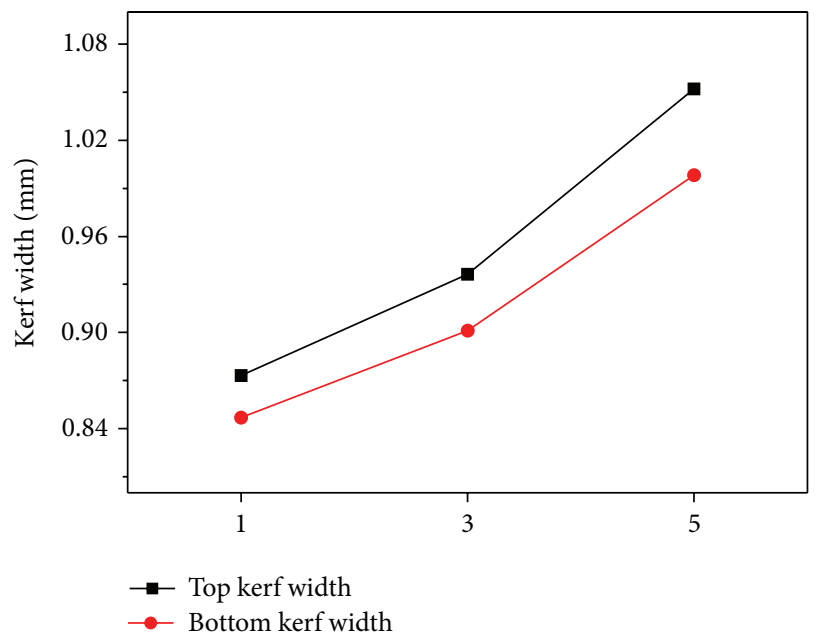

(d) Standoff distance $(\mathrm{mm})$

FIGURE 4: Main effect plots of top and bottom kerf width.

causes more abrasives particulates to impinge on the cutting surface during machining, thus contributing to increase in kerf width. However, the percentage contribution of abrasive concentration on top and bottom kerf width is $0.19 \%$ and $0.35 \%$, respectively.

3.3.4. Effect of SOD on Kerf Width. Figure 4(d) represents the effect of SOD on top and bottom kerf widths. Increase in SOD results in significant increase in kerf widths. As the jet is discharged through the nozzle, expansion and disintegration of the jet takes place due to outside boundary interaction. This leads to increase in top kerf width. As the jet kinetic energy reduces because of disintegration and expansion of the jet, the bottom kerf width is found to decrease. The percentage contribution of SOD on top and bottom kerf width is $52.16 \%$ and $44.92 \%$, respectively. The jet expansion increases with increase in the distance of jet traverse in air after ejecting from nozzle. Higher jet expansion leads to increase in top kerf width and also higher loss of jet kinetic energy. Hence, at higher SOD, the machining capability of the jet also decreases.

Further, it is found from the main effects plots shown in Figure 4 that the mean value of the top kerf width $(0.954 \mathrm{~mm})$ is higher than the bottom kerf width $(0.913 \mathrm{~mm})$. The difference in the mean kerf widths is observed to be $0.041 \mathrm{~mm}$.

3.4. Analysis of Variance (ANOVA) Results. The kerf widths were analyzed using ANOVA method to find the effect of process parameters at $95 \%$ confidence level using $F$ (variance ratio) statistics as shown in Table 5. It is observed that $F_{\text {calculated }}$ is greater than $F_{(\alpha=.005,6)}$ for the machining parameters such as SOD, jet pressure, and feed rate. A small variation of these parameters contributes to a considerable variation on the kerf width. Hence, it is clear from ANOVA that jet pressure, SOD, and feed rate are significant process parameters. However, for abrasive concentration, $F_{\text {calculated }}$ is found to be less than $F_{(\alpha=.005,6)}$. The effect of variation in 
TABLE 5: ANOVA for top and bottom kerf width.

\begin{tabular}{|c|c|c|c|c|c|c|c|c|c|}
\hline \multirow{2}{*}{ Source } & \multirow{2}{*}{ DF } & \multicolumn{4}{|c|}{ Top kerf width (TKW) } & \multicolumn{4}{|c|}{ Bottom kerf width (BKW) } \\
\hline & & SS & MS & $F$ & $\%$ SS & SS & MS & F & $\%$ SS \\
\hline Pressure $(A)$ & 2 & 0.07027 & 0.03514 & 14.08 & 24.72 & 0.04636 & 0.02318 & 9.14 & 19.68 \\
\hline Feed rate $(B)$ & 2 & 0.03521 & 0.01761 & 7.05 & 12.38 & 0.03609 & 0.01805 & 7.12 & 15.31 \\
\hline Abrasive concentration $(C)$ & 2 & 0.00054 & 0.00027 & 0.11 & 0.19 & 0.00084 & 0.00042 & 0.17 & 0.35 \\
\hline $\operatorname{SOD}(D)$ & 2 & 0.14829 & 0.07415 & 29.70 & 52.16 & 0.10588 & 0.05294 & 20.87 & 44.92 \\
\hline$A * B$ & 4 & 0.00368 & 0.00092 & 0.37 & 1.29 & 0.01212 & 0.01215 & 1.19 & 5.14 \\
\hline$A * C$ & 4 & 0.00481 & 0.00537 & 0.48 & 1.68 & 0.00618 & 0.00618 & 0.61 & 2.62 \\
\hline$B * C$ & 4 & 0.02149 & 0.00121 & 1.40 & 7.55 & 0.01299 & 0.01299 & 1.28 & 5.15 \\
\hline Error & 6 & 0.01497 & 0.00249 & - & 5.13 & 0.01521 & 0.00253 & - & 6.45 \\
\hline
\end{tabular}

DF: degree of freedom, MS: mean square, SS: sum of square, and \% SS: percentage contribution.

TABLE 6: Mean value of top kerf widths (mm).

\begin{tabular}{lccc}
\hline Control parameter/levels & 1 & 2 & 3 \\
\hline Pressure (MPa) & $\mathbf{0 . 8 8 5}$ & 0.972 & 1.01 \\
Feed rate (mm/min) & 0.995 & 0.964 & $\mathbf{0 . 9 0 6}$ \\
Abrasive concentration $(\%)$ & $\mathbf{0 . 9 4 8}$ & 0.958 & 0.957 \\
SOD (mm) & $\mathbf{0 . 8 7 4}$ & 0.937 & 1.053 \\
\hline
\end{tabular}

TABLE 7: Results of confirmation experiments.

\begin{tabular}{lccccc}
\hline Trials & 1 & 2 & 3 & 4 & 5 \\
\hline Top kerf width & 0.780 & 0.802 & 0.792 & 0.781 & 0.778 \\
\hline Bottom kerf width & 0.761 & 0.792 & 0.758 & 0.749 & 0.749 \\
\hline
\end{tabular}

abrasive concentration on kerf width is not significant. Based on the $F$ values, the significance of machining parameters can be ranked as follows: SOD (1), pressure (2), feed rate (3), and abrasive concentration (4). Further, it is observed from the interaction plot shown in Figure 5 and ANOVA values that there is no significant interaction effect between jet pressure with feed rate and jet pressure with abrasive concentration as well as between feed rate and abrasive concentration.

3.5. Optimization and Regression Modeling of AWJM Process Parameters. Process parameters were optimized to produce smallest kerf width on the workpiece. Using the experimental results shown in Table 4, the mean value of the top kerf width is calculated at each level of process parameters as shown in Table 6. It is seen that smallest kerf width is obtained at an operating pressure of $90 \mathrm{MPa}$, feed rate of $125 \mathrm{~mm} / \mathrm{min}$, SOD of $1 \mathrm{~mm}$, and $6 \%$ abrasive concentration. At these optimum settings of process parameters, the predicted top kerf width is $0.756 \pm 0.068 \mathrm{~mm}$ and bottom kerf width is $0.731 \pm 0.068 \mathrm{~mm}$. Further, the confirmation experiments were conducted and test results are shown in the Table 7 . It is seen that kerf width obtained by experiments agree well with the expected optimized kerf width.

A mathematical model is developed to establish relationship between the process parameters $\left(x_{1}\right.$ : pressure, $x_{2}$ : feed rate, $x_{3}$ : abrasive concentration, and $x_{4}:$ SOD) and response parameters, that is, TKW: $y_{\mathrm{TKW}}$ and BKW: $y_{\mathrm{BKW}}$. The main effect, squared terms, and interaction effect of process
TABLE 8: Test results of regression model.

\begin{tabular}{lllll}
\hline \multirow{2}{*}{ Trial } & \multicolumn{2}{c}{ Experimental } & \multicolumn{2}{c}{ Predicted } \\
& TKW & BKW & TKW & BKW \\
\hline 1 & 0.785 & 0.761 & 0.845 & 0.794 \\
2 & 0.776 & 0.748 & 0.864 & 0.827 \\
3 & 0.849 & 0.833 & 0.934 & 0.895 \\
4 & 0.821 & 0.802 & 0.856 & 0.831 \\
5 & 0.910 & 0.902 & 0.990 & 0.934 \\
\hline
\end{tabular}

parameters are considered in the modeling. The coefficients of determination $\left(R^{2}\right)$ for the fitted regression equations are $96.86 \%$ and $91.52 \%$ for TKW and BKW, respectively. The predicting accuracy of regression model is tested by conducting confirmation experiments within the range of operating parameters, that is, $90 \geq x_{1} \leq 150 ; 75 \geq x_{2} \leq 125 ; 6$ $\geq x_{3} \leq 14 ; 1 \geq x_{4} \leq 5$. The kerf widths predicted by regression model and the kerf widths obtained by experiments are shown in Table 8. The developed regression models are given below:

$$
\begin{aligned}
y_{\mathrm{TKW}}= & 0.086850+0.008726 x_{1}+0.005988 x_{2} \\
& -0.010031 x_{3}+0.000050 x_{4}-0.000020 x_{1} x_{2} \\
& +0.000076 x_{1} x_{3}+0.000552 x_{1} x_{4}+0.000096 x_{2} x_{3} \\
& -0.000559 x_{2} x_{4}-0.000486 x_{3} x_{4}-0.000030 x_{1}^{2} \\
& -0.000023 x_{2}^{2}-0.000302 x_{3}^{2}+0.006542 x_{4}^{2}
\end{aligned}
$$

$$
\begin{aligned}
y_{\mathrm{BKW}}= & 0.107786+0.009745 x_{1}+0.001111 x_{2} \\
& +0.005242 x_{3}+0.050461 x_{4}-0.000017 x_{1} x_{2} \\
& -0.000032 x_{1} x_{3}+0.000317 x_{1} x_{4}+0.000119 x_{2} x_{3} \\
& -0.000614 x_{2} x_{4}-0.002175 x_{3} x_{4}-0.000029 x_{1}^{2} \\
& -0.000001 x_{2}^{2}-0.000260 x_{3}^{2}+0.005417 x_{4}^{2} .
\end{aligned}
$$




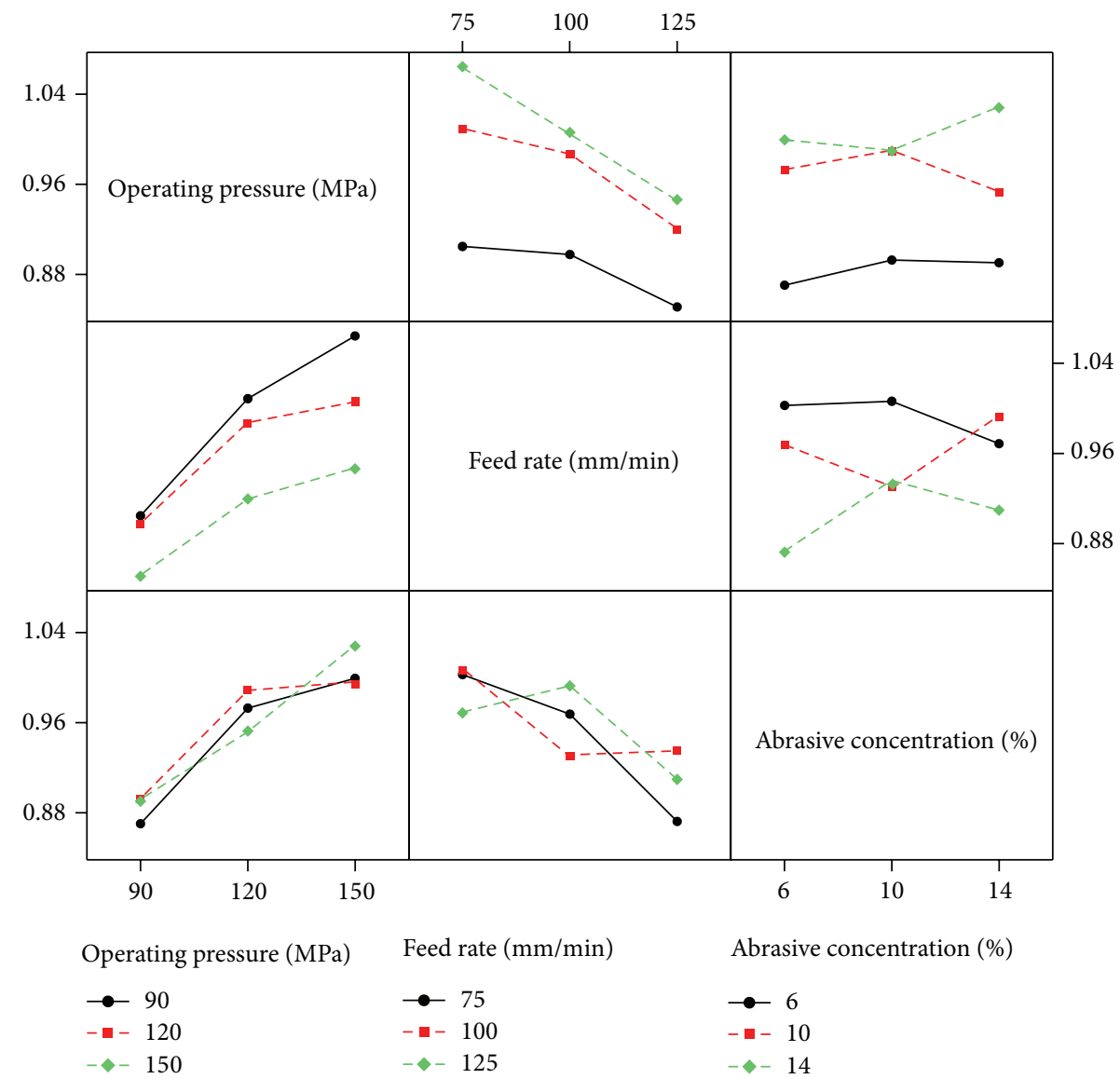

FIGURE 5: Interaction plot of process parameters.

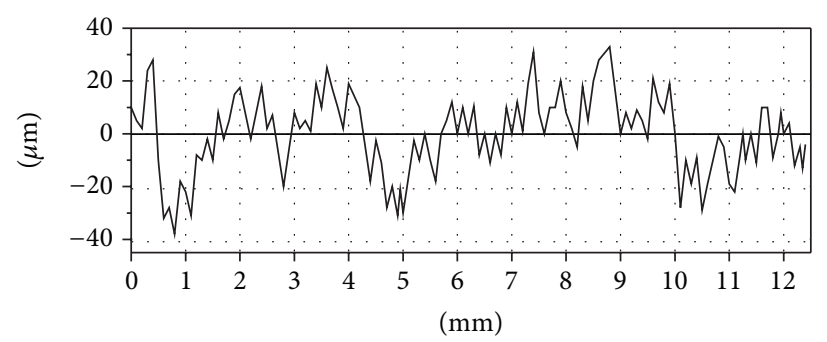

(a) $R_{a}$ values at the upper cut region $\left(R_{a}=3.73 \mu \mathrm{m}\right)$

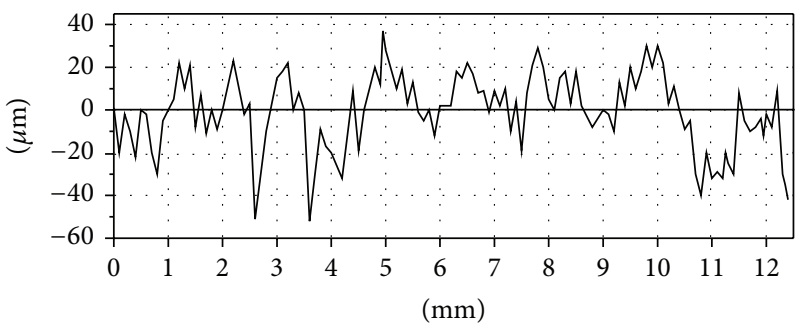

(b) $R_{a}$ values at the lower cut region $\left(R_{a}=4.82 \mu \mathrm{m}\right)$

FIGURE 6: Plots of surface roughness on cut surface.

\subsection{Surface Roughness and Morphology}

3.6.1. Surface Roughness. The roughness $\left(R_{a}\right)$ of the surface generated at optimum settings of machining parameters was measured at a distance of $1 \mathrm{~mm}$ from top and bottom edge of the machined surface. The surface roughness plots obtained by Taylor Hobson Surtronic $3^{+}$are shown in Figures 6(a) and 6(b). The plots reveal that the cut surface at jet entry region is smoother compared to jet exit. This is due to synergetic effect of loss of jet energy and addition of residual chips combined with abrasives when AWJ is penetrating through the workpiece.
3.6.2. Morphology. Morphological study has been carried out using SEM on the specimens that were machined at the optimum process settings which generate small kerf width. It is seen from Figure 7(a) that the top and bottom edges of the kerf are free from delamination. It is also observed from Figure 7(b) that there are inconsistent and nonuniform pits at few locations on top kerf due to collision between abrasive particles which richochiates from the edges. Further, SEM analysis is carried out to understand the microlevel of destruction in the composite. Figures $7(\mathrm{c})$ and $7(\mathrm{~d})$ show the morphology of cut surface when fibers are oriented at $90^{\circ}$ and are parallel to jet traverse, respectivly. It is seen that 


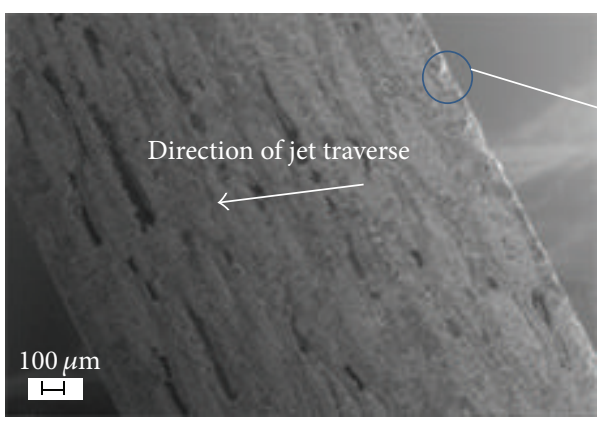

(a)

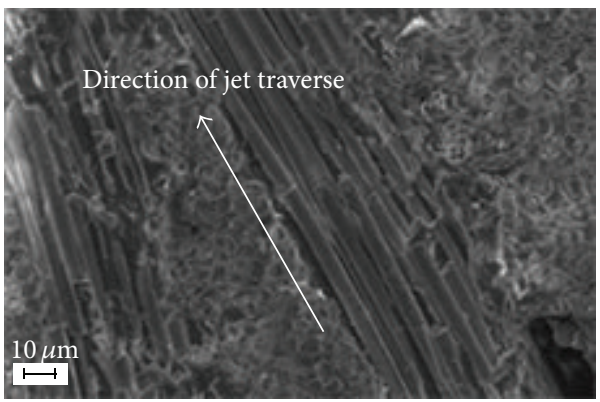

(c)

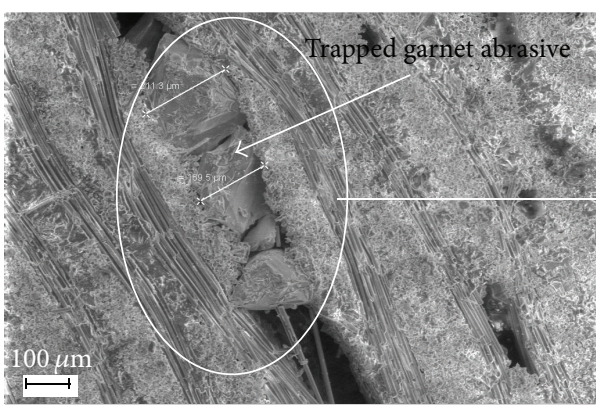

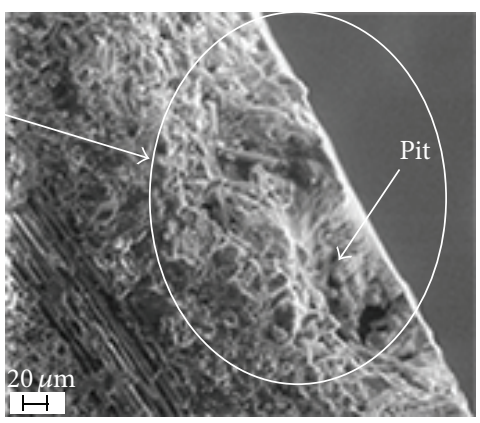

(b)

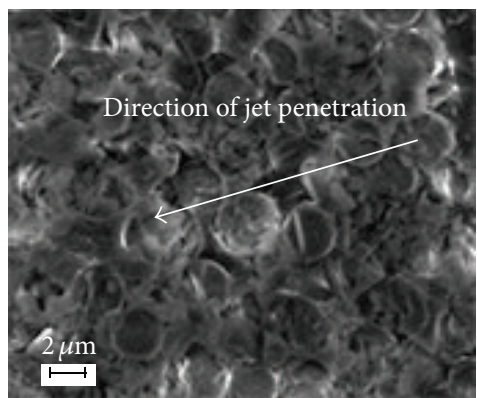

(d)

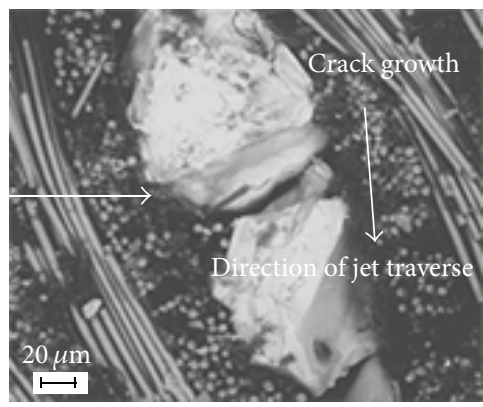

(e)

Figure 7: SEM images of (a) machined surface at the optimum process settings, (b) magnified view of top kerf damage, (c) fibers in plane of jet traverse, (d) fibers at normal to direction of jet traverse, and (e) Abrasive embedment on the surface machined at nonoptimum settings.

the fibers are cut accurately and no abrasive embeddment is found accoss the machined surface.

In addition, morphological analysis is also carried out on the cut surfaces that were machined at selected nonoptimum process settings (jet operating pressure: $150 \mathrm{MPa}$, feed rate: $75 \mathrm{~mm} / \mathrm{min}$, and SOD: $5 \mathrm{~mm}$ ) to compare the surface morphology. The cut surface exhibited the abrasive embeddment as shown in Figure 7(e) due to the increase in flow turbulance of the jet at higher operating pressure and SOD. A crack (length of 6 to 8 times the diameter of the abrasive particle) is found along the direction of jet traverse due to abrasive embedment. Further, it is seen from Figure 7(e) that the crack has widened due to the penetration and wedging action of abrasives into the surrounding fibers and the matrix leading to delamination. Also, a few chopped fibers are found in the crack and a few fibers were carried away by the jet. From the morphological analysis, it is concluded that the surface machined at optimum process settings produced the cut surface which is free from delamination.

\section{Conclusions}

The following conclusions have been drawn from the present research work.

(i) The kerf width increased with an increase in operating pressure (contribution: TKW, 24.72\% and BKW, $19.68 \%$ ) and standoff distance (contribution: TKW, $52.16 \%$ and BKW, 44.92\%), but it decreased with increase in feed rate (contribution: TKW, $12.38 \%$ and BKW, 15.31\%). Abrasive concentration has marginal effect on the kerf width.

(ii) The interaction effects of the process parameters are found to be insignificant. Hence, process parameters 
can be independently varied to get required kerf width.

(iii) Process parameters are optimized to get small kerf width and regression models are developed to predict the top and bottom kerf width with $R^{2}$ values of 96.86\% and $91.52 \%$ for TKW and BKW, respectively.

(iv) The morphological study revealed that there is no delamination of the surface machined at optimum process settings chosen to obtain small kerf as compared to that of the surface machined at nonoptimum process parameters.

\section{Conflict of Interests}

The authors declare that there is no conflict of interests regarding the publication of this paper.

\section{Acknowledgments}

The authors would like to acknowledge the support rendered by Industrial Mineral Co., Tuticorin, India, and Manipal University for their support in this research work.

\section{References}

[1] B. Shivamurthy, K. Udaya Bhat, and S. Anandhan, "Mechanical and sliding wear properties of multi-layered laminates from glass fabric/graphite/epoxy composites," Materials and Design, vol. 44, pp. 136-143, 2013.

[2] R. K. Goyal and A. Kadam, "Polyphenylene sulphide/graphite composites for emi shielding applications," Advanced Materials Letters, vol. 1, no. 2, pp. 143-147, 2010.

[3] S. Bhattacharya, R. P. Tandon, and V. K. Sachdev, "Electrical conduction of graphite filled high density polyethylene composites: experiment and theory," Journal of Materials Science, vol. 44, no. 9, pp. 2430-2433, 2009.

[4] R. Teti, "Machining of composite materials," CIRP AnnalsManufacturing Technology, vol. 51, no. 2, pp. 611-634, 2002.

[5] A. M. Abrão, P. E. Faria, J. C. C. Rubio, P. Reis, and J. P. Davim, "Drilling of fiber reinforced plastics: a review," Journal of Materials Processing Technology, vol. 186, no. 1-3, pp. 1-7, 2007.

[6] Y. H. Guu, H. Hocheng, N. H. Tai, and S. Y. Liu, "Effect of electrical discharge machining on the characteristics of carbon fiber reinforced carbon composites," Journal of Materials Science, vol. 36, no. 8, pp. 2037-2043, 2001.

[7] Z. L. Li, H. Y. Zheng, G. C. Lim, P. L. Chu, and L. Li, "Study on UV laser machining quality of carbon fibre reinforced composites," Composites Part A: Applied Science and Manufacturing, vol. 41, no. 10, pp. 1403-1408, 2010.

[8] J. Wang, "Abrasive waterjet machining of polymer matrix composites cutting performance, erosive process and predictive models," International Journal of Advanced Manufacturing Technology, vol. 15, no. 10, pp. 757-768, 1999.

[9] W. M. Andreas and R. Kovacevic, Principles of Abrasive Water Jet Machining, Spinger, London, UK, 1998.

[10] E. Huttunen-Saarivirta, F. H. Stott, V. Rohr, and M. Schütze, "Particle angularity effects on the elevated-temperature erosion-oxidation behaviour of aluminium diffusion coatings on 9\% Cr steel," Wear, vol. 261, no. 7-8, pp. 746-759, 2006.
[11] S. Yerramareddy and S. Bahadur, "Effect of operational variables, microstructure and mechanical properties on the erosion of Ti-6Al-4V," Wear, vol. 142, no. 2, pp. 253-263, 1991.

[12] M. S. ElTobgy, E. Ng, and M. A. Elbestawi, "Finite element modeling of erosive wear," International Journal of Machine Tools and Manufacture, vol. 45, no. 11, pp. 1337-1346, 2005.

[13] A. A. Khan and M. M. Haque, "Performance of different abrasive materials during abrasive water jet machining of glass," Journal of Materials Processing Technology, vol. 191, no. 1-3, pp. 404-407, 2007.

[14] M. K. Babu and O. V. K. Chetty, "A study on recycling of abrasives in abrasive water jet machining," Wear, vol. 254, no. 7-8, pp. 763-773, 2003.

[15] G. Holmqvist and U. Honsberg, "Sensitivity analysis of abrasive waterjet cutting economy," in Proceedings of the 19th International Conference on Water Jetting, pp. 273-287, Nottingham University, Nottingham, UK, October 2008.

[16] J. Folkes, "Waterjet-an innovative tool for manufacturing," Journal of Materials Processing Technology, vol. 209, no. 20, pp. 6181-6189, 2009.

[17] F. Boud, C. Carpenter, J. Folkes, and P. H. Shipway, "Abrasive waterjet cutting of a titanium alloy: the influence of abrasive morphology," Journal of Materials Processing Technology, vol. 210, no. 15, pp. 2197-2205, 2010.

[18] D. S. Srinivasu, D. A. Axinte, P. H. Shipway, and J. Folkes, "Influence of kinematic operating parameters on kerf geometry in abrasive waterjet machining of silicon carbide ceramics," International Journal of Machine Tools and Manufacture, vol. 49, no. 14, pp. 1077-1088, 2009.

[19] M. Junkar, B. Jurisevic, M. Fajdiga, and M. Grah, "Finite element analysis of single-particle impact in abrasive water jet machining," International Journal of Impact Engineering, vol. 32, no. 7, pp. 1095-1112, 2006.

[20] J. Wang and D. M. Guo, "A predictive depth of penetration model for abrasive waterjet cutting of polymer matrix composites," Journal of Materials Processing Technology, vol. 121, no. 2-3, pp. 390-394, 2002.

[21] D. K. Shanmugam, T. Nguyen, and J. Wang, "A study of delamination on graphite/epoxy composites in abrasive waterjet machining," Composites Part A, vol. 39, no. 6, pp. 923-929, 2008.

[22] M. A. Azmir and A. K. Ahsan, "Investigation on glass/epoxy composite surfaces machined by abrasive water jet machining," Journal of Materials Processing Technology, vol. 198, no. 1-3, pp. 122-128, 2008.

[23] M. A. Azmir and A. K. Ahsan, "A study of abrasive water jet machining process on glass/epoxy composite laminate," Journal of Materials Processing Technology, vol. 209, no. 20, pp. 61686173, 2009.

[24] A. Alberdi, A. Suárez, T. Artaza, G. A. Escobar-Palafox, and K. Ridgway, "Composite cutting with abrasive water jet," Procedia Engineering, vol. 63, pp. 421-429, 2013.

[25] N. Haghbin, J. K. Spelt, and M. Papini, "Abrasive waterjet micro-machining of channels in metals: comparison between machining in air and submerged in water," International Journal of Machine Tools and Manufacture, vol. 88, pp. 108-117, 2015.

[26] D. A. Axinte, D. S. Srinivasu, J. Billingham, and M. Cooper, "Geometrical modelling of abrasive waterjet footprints: a study for $90^{\circ}$ jet impact angle," CIRP Annals-Manufacturing Technology, vol. 59, no. 1, pp. 341-346, 2010. 
[27] M. C. Kong, S. Anwar, J. Billingham, and D. A. Axinte, "Mathematical modelling of abrasive waterjet footprints for arbitrarily moving jets: part I-single straight paths," International Journal of Machine Tools and Manufacture, vol. 53, no. 1, pp. 58-68, 2012.

[28] P. R. Vundavilli, M. B. Parappagoudar, S. P. Kodali, and S. Benguluri, "Fuzzy logic-based expert system for prediction of depth of cut in abrasive water jet machining process," Knowledge-Based Systems, vol. 27, pp. 456-464, 2012.

[29] A. M. Zain, H. Haron, and S. Sharif, "Estimation of the minimum machining performance in the abrasive waterjet machining using integrated ANN-SA," Expert Systems with Applications, vol. 38, no. 7, pp. 8316-8326, 2011.

[30] J. Billingham, C. B. Miron, D. A. Axinte, and M. C. Kong, "Mathematical modelling of abrasive waterjet footprints for arbitrarily moving jets: part II-overlapped single and multiple straight paths," International Journal of Machine Tools and Manufacture, vol. 68, pp. 30-39, 2013.

[31] C. Narayanan, R. Balz, D. A. Weiss, and K. C. Heiniger, "Modelling of abrasive particle energy in water jet machining," Journal of Materials Processing Technology, vol. 213, no. 12, pp. 2201-2210, 2013.

[32] H. Nouraei, K. Kowsari, J. K. Spelt, and M. Papini, "Surface evolution models for abrasive slurry jet micro-machining of channels and holes in glass," Wear, vol. 309, no. 1-2, pp. 65-73, 2014.

[33] M. K. Babu and O. V. K. Chetty, "A study on the use of single mesh size abrasives in abrasive waterjet machining," The International Journal of Advanced Manufacturing Technology, vol. 29, no. 5-6, pp. 532-540, 2006. 

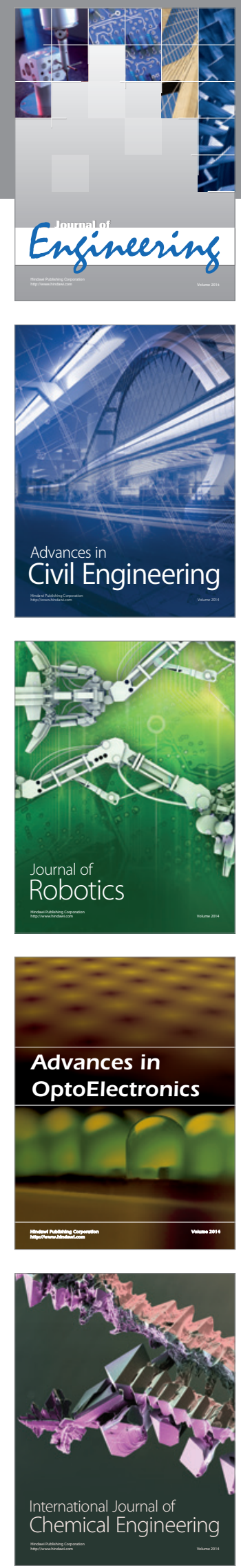

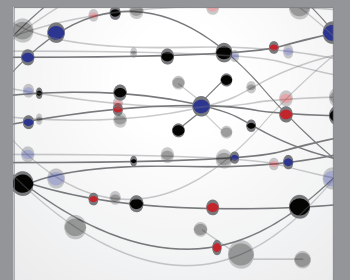

The Scientific World Journal
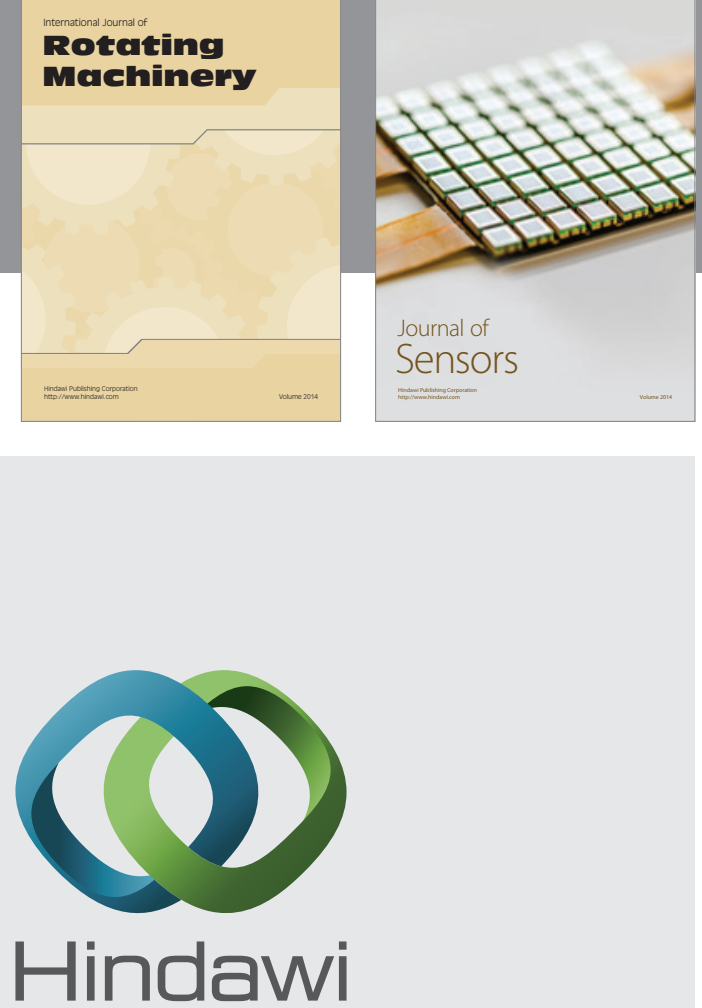

Submit your manuscripts at http://www.hindawi.com
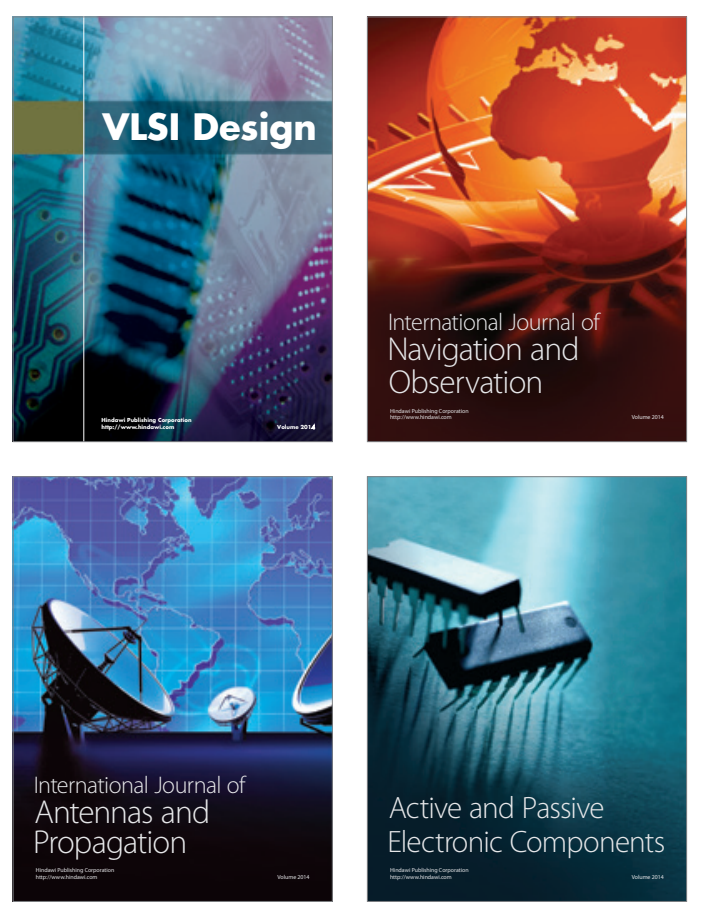
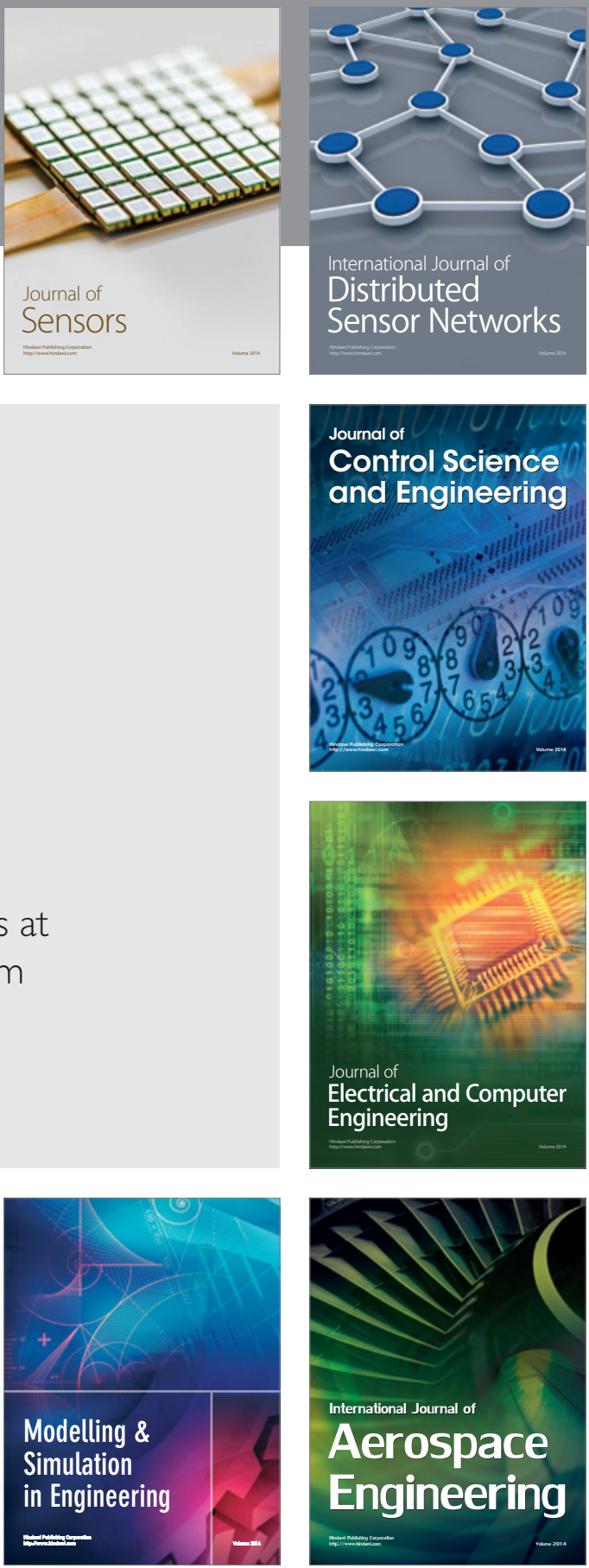

Journal of

Control Science

and Engineering
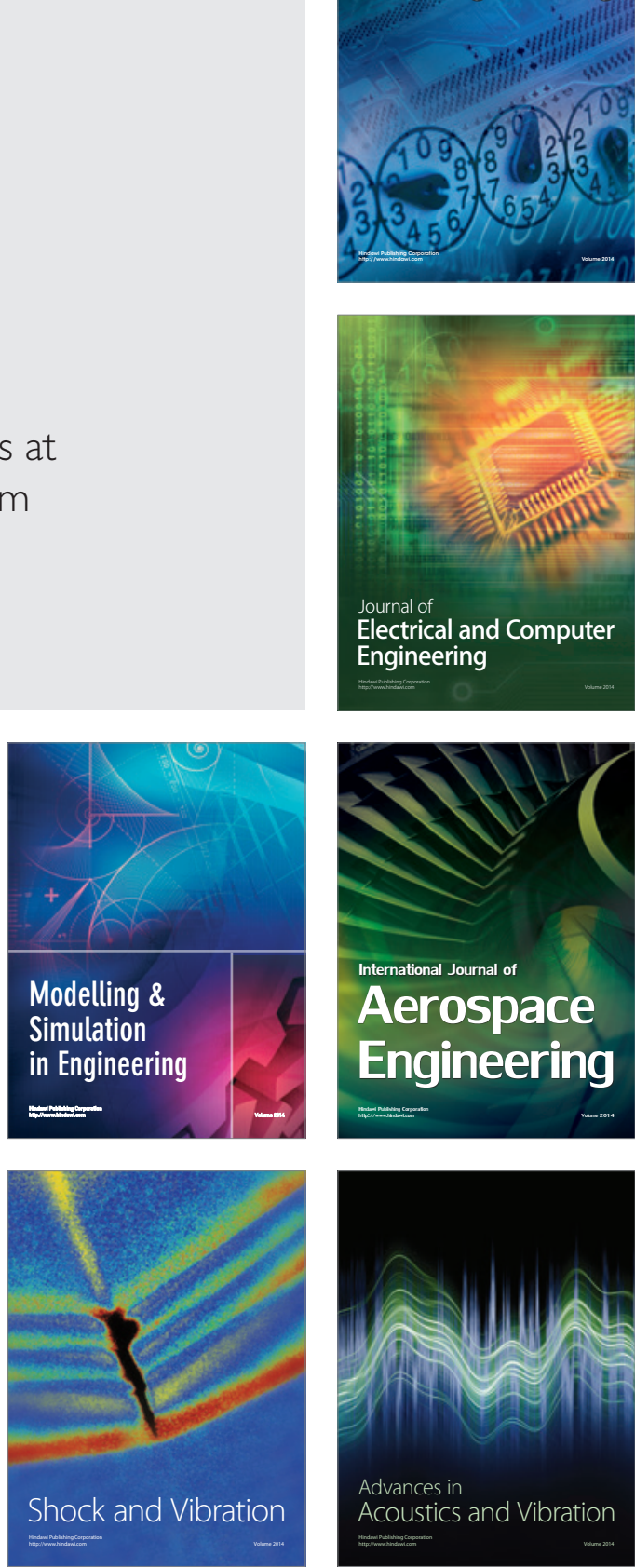